\title{
Giardiasis outbreaks in the United States, 1971-2011
}

\author{
E. A. ADAM ${ }^{1,2 *}$, J. S. YODER ${ }^{1}$, L. H. GOULD ${ }^{1}$, M. C. $\operatorname{HLAVSA}^{1}$ AND \\ J. W. GARGANO ${ }^{1}$ \\ ${ }^{1}$ Division of Foodborne, Waterborne, and Environmental Diseases, National Center for Emerging and Zoonotic \\ Infectious Diseases, Centers for Disease Control and Prevention, Atlanta, GA, USA \\ ${ }^{2}$ Oak Ridge Institute for Science and Education, Oak Ridge, TN, USA
}

Received 15 July 2015; Final revision 14 October 2015; Accepted 11 November 2015; first published online 11 January 2016

\section{SUMMARY}

Giardia intestinalis is the leading parasitic aetiology of human enteric infections in the United States, with an estimated 1.2 million cases occurring annually. To better understand transmission, we analysed data on all giardiasis outbreaks reported to the Centers for Disease Control and Prevention for 1971-2011. The 242 outbreaks, affecting 41000 persons, resulted from waterborne $(74 \cdot 8 \%)$, foodborne $(15 \cdot 7 \%)$, person-to-person $(2 \cdot 5 \%)$, and animal contact $(1 \cdot 2 \%)$ transmission. Most $(74.6 \%)$ waterborne outbreaks were associated with drinking water, followed by recreational water $(18 \cdot 2 \%)$. Problems with water treatment, untreated groundwater, and distribution systems were identified most often during drinking water-associated outbreak investigations; problems with water treatment declined after the 1980s. Most recreational water-associated outbreaks were linked to treated swimming venues, with pools and wading pools implicated most often. Produce was implicated most often in foodborne outbreaks. Additionally, foods were most commonly prepared in a restaurant and contaminated by a food handler. Lessons learned from examining patterns in outbreaks over time can help prevent future disease. Groundwater and distribution system vulnerabilities, inadequate pool disinfection, fruit and vegetable contamination, and poor food handler hygiene are promising targets for giardiasis prevention measures.

Key words: Community outbreaks, foodborne infections, Giardia lamblia, waterborne infections, zoonoses.

\section{INTRODUCTION}

Giardia intestinalis is the leading parasitic aetiology of human enteric infections in the United States [1]. An estimated 1.2 million cases of giardiasis and 3581 hospitalizations occur annually [2], resulting in US\$34 million in direct hospitalization costs [3]. Giardiasis is typically characterized by gastrointestinal symptoms

\footnotetext{
* Author for corresponding: Ms. E. A. Adam, 1600 Clifton Rd NE MS C-09, Atlanta GA 30029, USA.

(Email: wsi7@cdc.gov)
}

including diarrhoea, bloating, and abdominal cramps; asymptomatic infections also occur frequently $[4,5]$. Ingestion of as few as ten Giardia cysts has been shown to cause infection in a dosing study [6]. Cysts are excreted in the faeces of an infected person or animal [7]. Infected individuals might excrete up to a billion cysts in their stool each day for several months, and cysts are immediately infectious upon excretion $[6,8,9]$. Cysts are environmentally stable and moderately resistant to chlorine disinfection, and thus can survive in water, food, or on surfaces for prolonged periods of time $[4,7]$. 
US national data on reported cases of giardiasis show a gradual decrease in disease rates from 1996 to 2001; subsequently, rates from 2002 to 2010 remained relatively stable, coinciding with the disease becoming nationally notifiable in 2002 [10]. A recent decline in reported cases during 2011 to 2012 has been noted [11]. For most cases of illness, the source of the infection cannot be identified, and thus data from national case reports cannot be used to describe pathogen transmission [10]. Insight into the major drivers of Giardia transmission could inform effective prevention messages and measures.

The transmission pathways of giardiasis in the United States have not previously been well-described. Outbreak investigations provide an opportunity to gain insight into pathogen transmission. In the United States, local or state public health officials detect and investigate clusters of illnesses to determine whether there is a common source, as is the case in an outbreak; once an outbreak is detected, the investigation is used to find related cases of illnesses, to control the outbreak, and to prevent similar occurrences from happening in the future. Investigation methods and jurisdictions vary by state and locality, depending on local priorities and resources. States occasionally request epidemiological or laboratory assistance from the federal Centers for Disease Control and Prevention (CDC); CDC does not direct or participate in outbreak investigations without an invitation. States voluntarily report outbreak investigation summary information to CDC, and CDC has periodically published reports on disease outbreaks by mode of transmission since the early 1970s [12-15]. To date, there has been no overarching evaluation over several decades of the impact of changes to policies and surveillance activities, pathogen-specific risk factors, or patterns in outbreak occurrence. To gain a better understanding of Giardia transmission across all modes of transmission, we reviewed and analysed national data on all giardiasis outbreaks reported to CDC for 1971-2011.

\section{METHODS}

An outbreak was defined as two or more cases of giardiasis that were epidemiologically linked by time or location of exposure to a common source. Outbreaks were investigated by and at the discretion of local or state public health agencies, and states voluntarily reported outbreaks to CDC surveillance systems. Since 2009, enteric disease outbreaks have been reported to $\mathrm{CDC}$ via the electronic National
Outbreak Reporting System (NORS) [12]. Before 2009, waterborne outbreaks were reported to CDC using standard paper-based reporting forms, starting in 1971 for drinking water-associated outbreaks and in 1978 for recreational water-associated outbreaks. Foodborne outbreaks were reported to CDC using standard paper-based reporting forms starting in 1973, and using standard electronic forms starting in 1998. Systematic reporting of enteric disease outbreaks resulting from person-to-person, animal contact, environmental, and unknown transmission modes started with NORS implementation, although some outbreaks from these transmission modes were reported to CDC's foodborne outbreak surveillance system before 2009.

For this review and analysis, we included data from all outbreak reports finalized as of 25 February 2013 in CDC outbreak surveillance systems for which at least one listed aetiology was Giardia and the date of illness onset of the earliest case occurred during 1971-2011. To facilitate characterization of outbreaks, we analysed data elements that were consistently collected across the different outbreak surveillance systems and over time, including: state, year and month of illness onset of the earliest case, the number of outbreak-associated cases, the implicated pathogen(s), the setting of the outbreak, and the modes and vehicles of transmission. To describe contributing factors, we summarized data specific to each transmission mode, such as the type of drinking water system or the food preparation setting.

Descriptors for foodborne and other enteric disease outbreaks were maintained as reported to CDC. For waterborne outbreaks, we used the implicated water vehicle to classify the outbreaks as being associated with drinking water, recreational water, or other water. The drinking water category included outbreaks linked to contaminated drinking water or commercially bottled water. Implicated drinking water systems were categorized according to the U.S. Environmental Protection Agency (EPA) water system definitions for community, non-community, individual, or commercially bottled water [16]. Drinking water source was defined as groundwater, surface water, mixed, or unknown. Outbreak deficiencies, which characterize water system problems implicated during outbreak investigations, were previously assigned by a panel of CDC and EPA scientists that routinely reviews the outbreak reports. Outbreaks resulting from problems with the source water were classified as having untreated surface water or untreated groundwater deficiency. 
Table 1. Giardiasis outbreaks reported in the United States (1971-2011), by mode of transmission ( $n=242)$

\begin{tabular}{|c|c|c|c|c|c|c|c|}
\hline \multirow[b]{2}{*}{ Transmission mode } & \multicolumn{2}{|c|}{ Outbreaks } & \multicolumn{2}{|l|}{ Cases } & \multicolumn{3}{|c|}{ No. of cases per outbreak } \\
\hline & $n$ & $(\%)$ & $n$ & $(\%)$ & Median & Minimum & Maximum \\
\hline All modes & 242 & $(100)$ & 40939 & $(100)$ & 18 & 2 & 5449 \\
\hline Waterborne* & 181 & $(74 \cdot 8)$ & 40027 & $(97 \cdot 8)$ & 23 & 2 & 5449 \\
\hline Foodborne $\dagger$ & 38 & $(15 \cdot 7)$ & 825 & $(2 \cdot 0)$ & 16 & 2 & 82 \\
\hline Person-to-person & 6 & $(2 \cdot 5)$ & 28 & $(0 \cdot 1)$ & 4 & 3 & 9 \\
\hline Animal contact & 3 & $(1 \cdot 2)$ & 20 & $(0 \cdot 0)$ & 6 & 2 & 12 \\
\hline Unknown & 14 & $(5 \cdot 8)$ & 39 & $(0 \cdot 1)$ & 2 & 2 & 6 \\
\hline
\end{tabular}

* Systematic waterborne disease outbreak reporting began in 1971.

$\uparrow$ Systematic foodborne disease outbreak reporting began in 1973.

\$ Systematic enteric disease outbreak reporting from person-to-person, animal contact, environmental, and unknown transmission modes began in 2009. There were no Giardia outbreaks reported with environmental mode of transmission.

Outbreaks caused by circumstances at the treatment facility that allowed contamination, such as disruption in disinfection, were assigned treatment deficiency. Outbreaks involving problems in the distribution system under the jurisdiction of the water utility (e.g. crossconnection and backflow) were assigned distribution system deficiency. Outbreaks resulting from problems outside the jurisdiction of the water utility were assigned plumbing deficiency (e.g. cross-connection and backflow within a building) or deficiency at point-of-use (e.g. contamination of a container). The recreational water category included outbreaks linked to contaminated untreated water (e.g. in lakes) or treated water (e.g. chlorinated or filtered) in at least partially man-made venues (e.g. in pools). The remaining waterborne outbreak category included outbreaks linked to consumption of non-potable or non-recreational water (e.g. drinking directly from a stream) and outbreaks in which the particular contaminated water source was undetermined. Data were summarized descriptively using SAS v. 9.3 (SAS Institute Inc., USA). To analyse the potential impact of drinking water regulations, the time period was divided into two periods: before implementation of the Surface Water Treatment Rule (SWTR) (1971-1989) and post-SWTR (1990-2011), a period in which several new microbial rules were implemented. Frequencies were compared using $\chi^{2}$ tests or Fisher's exact tests when expected cell counts were $<5$, and differences in mean number of annual outbreaks were evaluated using $t$ tests.

\section{RESULTS}

Giardia was implicated in 242 reported outbreaks during 1971-2011, which resulted from waterborne $(n=181$, $74 \cdot 8 \%)$, foodborne $(n=38,15 \cdot 7 \%)$, person-to-person $(n=6,2 \cdot 5 \%)$, animal contact $(n=3,1 \cdot 2 \%)$, and unknown $(n=14,5 \cdot 8 \%)$ transmission (Table 1$)$. The 242 outbreaks were associated with 40939 cases of illness. The median number of cases per outbreak was 18 (range 2-5449). Waterborne outbreaks resulted in the largest total number of cases $(n=40027,97 \cdot 8 \%)$ and the highest median number of cases per outbreak (23 cases).

Waterborne giardiasis outbreaks peaked in the early 1980s, which correlated with the implementation of an EPA-funded project to support intensive waterborne disease surveillance in Colorado, Vermont, and Washington for 2-year periods during 1980-1983 (Fig. 1) [17]. Following the implementation of NORS in 2009, reporting of giardiasis outbreaks resulting from person-to-person, animal contact, and unknown modes of transmission increased.

Giardiasis outbreaks occurred year-round but displayed a summer peak (Fig. 2). About half of all reported outbreaks started during June-September (51.6\%), with July the most frequent month (17.8\%). The summer peak was most pronounced for outbreaks associated with recreational water; only three of 33 outbreaks occurred outside the months of JuneSeptember.

Three-quarters of waterborne giardiasis outbreaks $(n=135, \quad 74.6 \%)$ were associated with drinking water, followed by recreational water $(n=33,18 \cdot 2 \%)$ and other water $(n=13,7 \cdot 2 \%)$. More than two-thirds of all reported drinking water-associated outbreaks (96 outbreaks) occurred during the 19-year period 1971-1989; the remaining 39 outbreaks occurred during the 22-year period 1990-2011 (Fig. 3a). The mean annual number of reported drinking water-associated outbreaks decreased during the second time period 


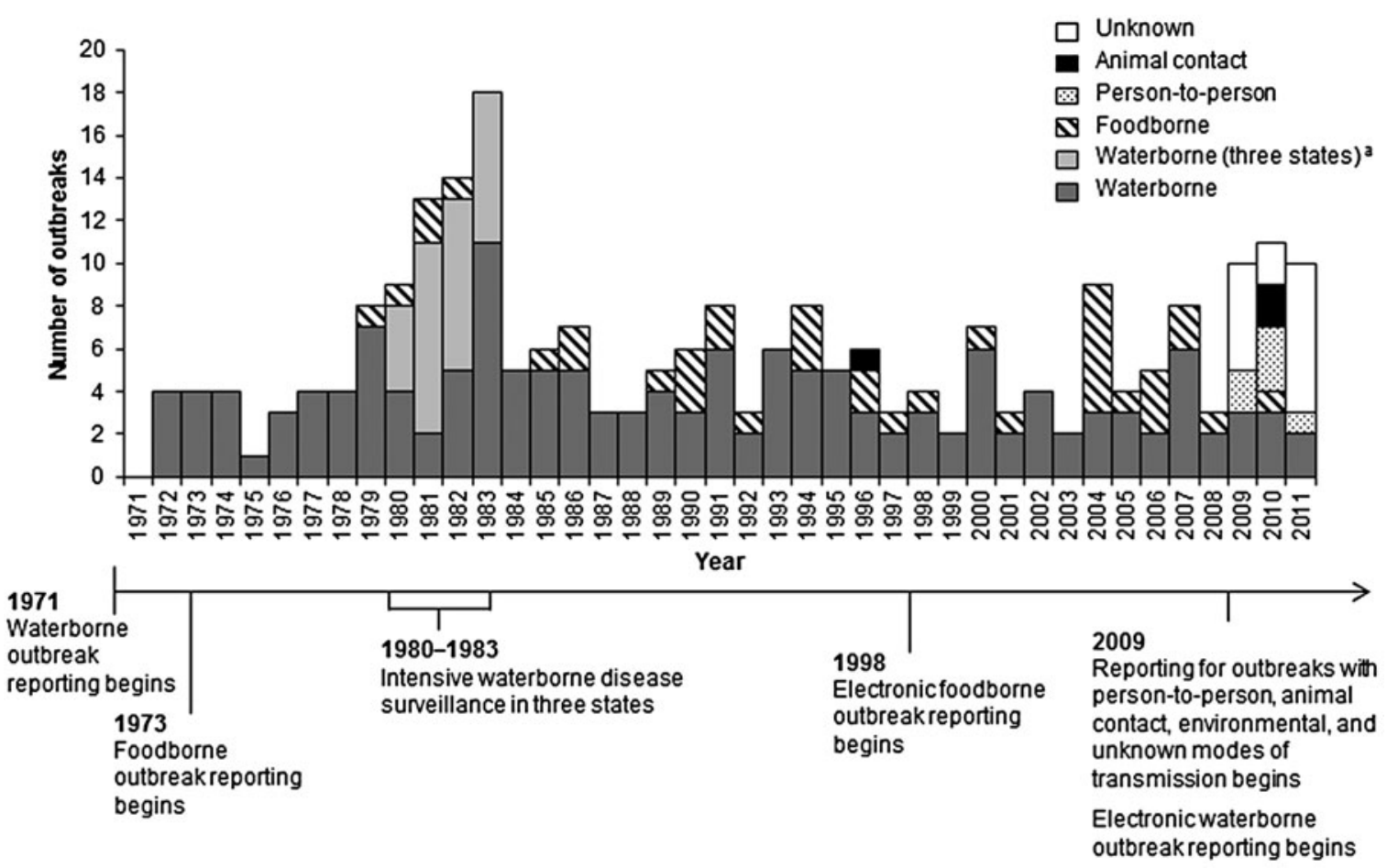

Fig. 1. Giardiasis outbreaks, by year and mode of transmission, United States, 1971-2011 $(n=242)$. The timeline below the figure outlines key changes in disease surveillance activities and systems. ${ }^{\text {a }}$ Waterborne outbreaks reported from Colorado, Vermont, and Washington; these states received 2-year funding from the U.S. Environmental Protection Agency to support intensive waterborne disease surveillance.

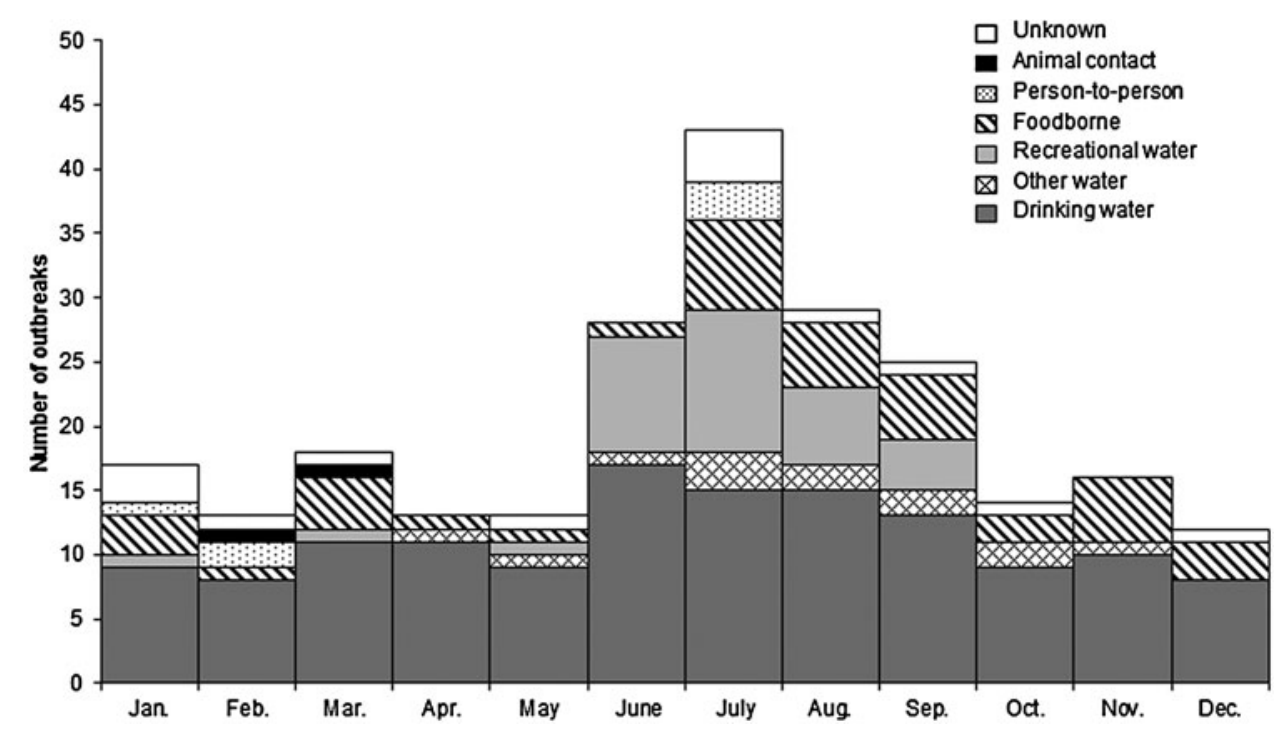

Fig. 2. Giardiasis outbreaks, by mode of transmission and month of first reported illness, United States, 1971-2011 $(n=241)$. Information on the month of first illness was missing for one outbreak associated with animal contact transmission.

(5.3 in 1971-1989 vs. 1.8 in $1990-2011, P<0.001$ ); this difference was less pronounced but still evident after excluding outbreaks that occurred during 1980-1983 from the three states with intensive waterborne disease surveillance activities (3.9 vs. 1·8, $P<0 \cdot 001)$. The first reported recreational waterassociated giardiasis outbreak occurred in 1985; since that time, the annual number of reported 

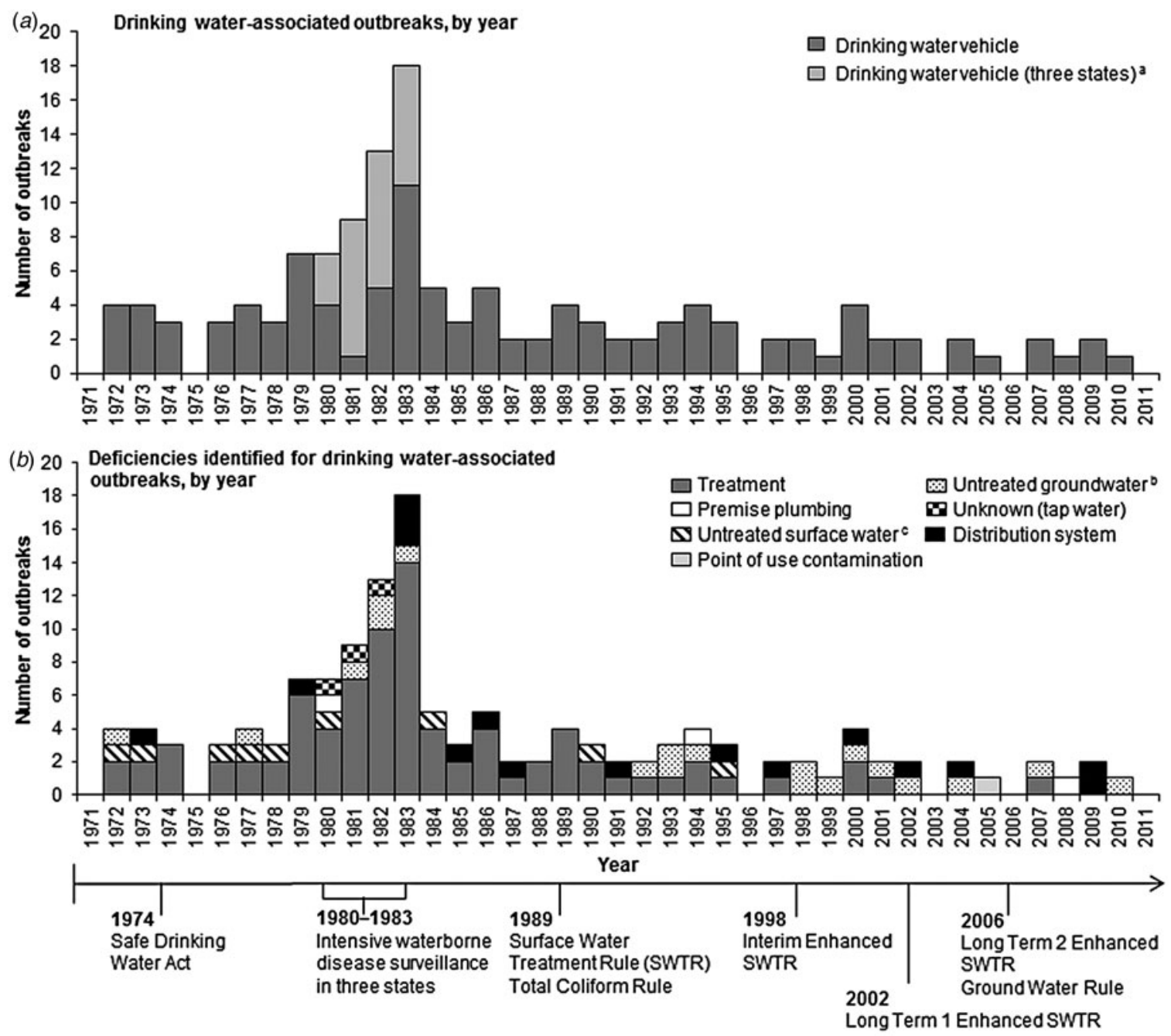

Fig. 3. Waterborne giardiasis outbreaks, by year, water vehicle, and outbreak deficiency, United States, 1971-2011. (a)


Colorado, Vermont, and Washington; these states received 2-year funding from the U.S. Environmental Protection Agency to support intensive waterborne disease surveillance. $(b)$ Deficiencies identified during drinking water outbreak investigations, by year, and timeline of key drinking water regulations and surveillance activities; each deficiency represents one outbreak $(n=135) .{ }^{\mathrm{b}}$ One outbreak was assigned an additional distribution system deficiency. ${ }^{\mathrm{c}}$ One outbreak was assigned an additional plumbing deficiency.

recreational water-associated outbreaks ranged from zero to four.

For drinking water-associated outbreaks, plotting the deficiencies identified over the 41-year period revealed changes in the causes of outbreaks over time (Fig. 3b). Overall, the most common deficiencies were treatment $(62 \cdot 2 \%)$, untreated groundwater source $(13 \cdot 3 \%)$, and distribution system deficiencies (11.9\%). Deficiencies in water treatment were identified for almost three-quarters $(74 \cdot 0 \%)$ of the pre-1990 drinking water-associated outbreaks and one-third $(33 \cdot 3 \%)$ of outbreaks that occurred during 1990-2011 $\left(\chi^{2}=19 \cdot 5\right.$, $P<0.001)$. The mean annual number of outbreaks assigned treatment deficiencies also decreased after the 1980 s $(4 \cdot 2$ vs. $0 \cdot 7, P<0 \cdot 001)$. The proportions of outbreaks assigned untreated groundwater source deficiencies $(6 \cdot 3 \%$ in $1971-1989$ vs. $33 \cdot 3 \%$ in 1990 2011, $\left.\chi^{2}=16 \cdot 8, P<0 \cdot 001\right)$ and distribution system deficiencies $(8 \cdot 3 \%$ for $1971-1989$ vs. $20 \cdot 5 \%$ for 1990 2011, Fisher's exact $P=0 \cdot 074$ ) increased after 1989, but the mean annual numbers of outbreaks assigned these deficiencies did not differ by time period. The last outbreak associated with an untreated surface water deficiency occurred in 1995.

The majority of reported drinking water-associated outbreaks and outbreak cases involved community 
Table 2. Aetiology, water system, water source, and deficiencies of drinking water-associated giardiasis outbreaks $(n=135)$ and outbreak cases $(n=30237)$, United States, 1971-2011

\begin{tabular}{|c|c|c|c|c|}
\hline \multirow[b]{2}{*}{ Characteristic/category } & \multicolumn{2}{|c|}{ Outbreaks } & \multicolumn{2}{|l|}{ Cases } \\
\hline & $n$ & $(\%)$ & $n$ & $(\%)$ \\
\hline \multicolumn{5}{|l|}{ Aetiology } \\
\hline Giardia only & 127 & $(94 \cdot 1)$ & 28222 & $(93 \cdot 3)$ \\
\hline Giardia and other pathogens* & 8 & $(5 \cdot 9)$ & 2015 & $(6 \cdot 7)$ \\
\hline \multicolumn{5}{|l|}{ Water system ${ }^{\dagger}$} \\
\hline Community & 92 & $(68 \cdot 1)$ & 25329 & $(83 \cdot 8)$ \\
\hline Non-community & 30 & $(22 \cdot 2)$ & 3367 & $(11 \cdot 1)$ \\
\hline Individual & 11 & $(8 \cdot 1)$ & 50 & $(0 \cdot 2)$ \\
\hline Non-community and individual & 1 & $(0 \cdot 7)$ & 1450 & $(4 \cdot 8)$ \\
\hline Commercially bottled water & 1 & $(0 \cdot 7)$ & 41 & $(0 \cdot 1)$ \\
\hline \multicolumn{5}{|l|}{ Water sourcet } \\
\hline Surface water & 88 & $(65 \cdot 2)$ & 23948 & $(79 \cdot 2)$ \\
\hline Groundwater & 42 & $(31 \cdot 1)$ & 5804 & $(19 \cdot 2)$ \\
\hline Mixed & 2 & $(1 \cdot 5)$ & 312 & $(1 \cdot 0)$ \\
\hline Unknown & 3 & $(2 \cdot 2)$ & 173 & $(0 \cdot 6)$ \\
\hline \multicolumn{5}{|l|}{ Deficiency§ } \\
\hline Treatment & 84 & $(62 \cdot 2)$ & 23697 & $(78 \cdot 4)$ \\
\hline Untreated groundwater & 18 & $(13 \cdot 3)$ & 368 & $(1 \cdot 2)$ \\
\hline Distribution system & 16 & $(11 \cdot 9)$ & 3818 & $(12 \cdot 6)$ \\
\hline Untreated surface water & 8 & $(5 \cdot 9)$ & 197 & $(0 \cdot 7)$ \\
\hline Plumbing & 3 & $(2 \cdot 2)$ & 365 & $(1 \cdot 2)$ \\
\hline Untreated groundwater and distribution system & 1 & $(0 \cdot 7)$ & 1450 & $(4 \cdot 8)$ \\
\hline Untreated surface water and plumbing & 1 & $(0 \cdot 7)$ & 189 & $(0 \cdot 6)$ \\
\hline Point-of-use contamination & 1 & $(0 \cdot 7)$ & 41 & $(0 \cdot 1)$ \\
\hline Unknown (tap water) & 3 & $(2 \cdot 2)$ & 112 & $(0 \cdot 4)$ \\
\hline
\end{tabular}

* Multiple aetiological agents were identified during investigations of eight outbreaks. Giardia and Cryptosporidium were identified in two outbreaks, Giardia and Campylobacter were identified in one outbreak, Giardia, Campylobacter, and Entamoeba were identified in one outbreak, Giardia, Campylobacter, and norovirus were identified in one outbreak, Giardia and Entamoeba were identified in one outbreak, Giardia and Salmonella were identified in one outbreak, and Giardia, Shigella, Cryptoprodium, and Clostridium were identified in one outbreak.

$\dagger$ Community and non-community systems are public water systems that are operated by a water utility and regulated for safety by the U.S. Environmental Protection Agency (EPA). Individual water systems are small systems that are not operated by a water utility and are not regulated for safety by the EPA.

† Surface water sources include lakes, rivers, reservoirs, and ponds. Groundwater sources include wells, springs, and other sources that extract water from an aquifer. Mixed sources are made up of both groundwater and surface water sources. $\S$ Deficiencies are identified by CDC and EPA scientists that review the outbreak reports; assigned deficiencies provide information about how the water became contaminated and help explain why the outbreak occurred.

water systems $(68 \cdot 1 \%$ of outbreaks, $83 \cdot 8 \%$ of outbreak cases) and systems with a surface water source $(65 \cdot 2 \%$ of outbreaks, $79 \cdot 2 \%$ of outbreak cases) (Table 2). Drinking water-associated outbreaks most frequently involved systems serving a community/municipality $(43.9 \%)$, resort $(9 \cdot 5 \%)$, camp/cabin/recreational area $(8 \cdot 8 \%)$, or private residence $(7 \cdot 4 \%)$.

Most recreational water-associated outbreaks $(n=22,66 \cdot 7 \%)$ and outbreak cases $(n=9295,96 \cdot 5 \%)$ were linked to treated recreational water venues (Table 3). Giardia was the only pathogen identified for most of these outbreaks $(72.7 \%$ for both treated and untreated water), but most cases of illness resulted from outbreaks of multiple aetiologies $(93.2 \%$ in treated water and $67.9 \%$ in untreated water). Of treated recreational water-associated outbreaks, the most common swimming venues were pools $(50.0 \%)$ and wading pools $(36 \cdot 4 \%)$. Most $(91 \cdot 0 \%)$ outbreak cases resulted from three waterpark-associated outbreaks; two of these outbreaks, accounting for $8449(90.9 \%)$ of all treated recreational water-associated outbreak cases, were caused by aetiological agents Giardia and Cryptosporidium. Among the untreated recreational water-associated outbreaks, most outbreaks 
Table 3. Aetiology, swimming venue, and setting of recreational water-associated giardiasis outbreaks $(n=33)$ and outbreak cases ( $n=9635)$, by treatment type, United States, 1971-2011

\begin{tabular}{|c|c|c|c|c|c|c|c|c|c|c|}
\hline \multirow[b]{3}{*}{ Characteristic } & \multicolumn{5}{|l|}{ Treated recreational water } & \multicolumn{5}{|c|}{ Untreated recreational water } \\
\hline & \multirow[b]{2}{*}{ Category } & \multicolumn{2}{|c|}{ Outbreaks } & \multicolumn{2}{|l|}{ Cases } & \multirow[b]{2}{*}{ Category } & \multicolumn{2}{|c|}{ Outbreaks } & \multicolumn{2}{|c|}{ Cases } \\
\hline & & $n$ & $(\%)$ & $n$ & $(\%)$ & & $n$ & $(\%)$ & $n$ & $(\%)$ \\
\hline All outbreaks & & 22 & $(66 \cdot 7)$ & 9295 & $(96 \cdot 5)$ & & 11 & $(33 \cdot 3)$ & 340 & $(3 \cdot 5)$ \\
\hline Aetiology & $\begin{array}{l}\text { Giardia only } \\
\text { Giardia and other } \\
\text { pathogens* }\end{array}$ & $\begin{array}{r}16 \\
6\end{array}$ & $\begin{array}{l}(72 \cdot 7) \\
(27 \cdot 3)\end{array}$ & $\begin{array}{r}632 \\
8663\end{array}$ & $\begin{array}{r}(6 \cdot 8) \\
(93 \cdot 2)\end{array}$ & $\begin{array}{l}\text { Giardia only } \\
\text { Giardia and other } \\
\text { pathogens* }\end{array}$ & $\begin{array}{l}8 \\
3\end{array}$ & $\begin{array}{l}(72 \cdot 7) \\
(27 \cdot 3)\end{array}$ & $\begin{array}{l}109 \\
231\end{array}$ & $\begin{array}{l}(32 \cdot 1) \\
(67 \cdot 9)\end{array}$ \\
\hline Venue & $\begin{array}{l}\text { Pool } \\
\text { Wading pool } \\
\text { Interactive outdoor } \\
\text { fountain } \\
\text { Wading pool, wave pool } \\
\text { Unknown }\end{array}$ & $\begin{array}{r}11 \\
8 \\
1\end{array}$ & $\begin{array}{r}(50 \cdot 0) \\
(36 \cdot 4) \\
(4 \cdot 5) \\
(4 \cdot 5) \\
(4 \cdot 5)\end{array}$ & $\begin{array}{r}513 \\
3273 \\
55 \\
5449 \\
5\end{array}$ & $\begin{array}{r}(5 \cdot 5) \\
(35 \cdot 2) \\
(0 \cdot 6) \\
(58 \cdot 6) \\
(0 \cdot 1)\end{array}$ & $\begin{array}{l}\text { Lake } \\
\text { River } \\
\text { Unknown }\end{array}$ & $\begin{array}{l}8 \\
2 \\
1\end{array}$ & $\begin{array}{r}(72 \cdot 7) \\
(18 \cdot 2) \\
(9 \cdot 1)\end{array}$ & $\begin{array}{r}322 \\
8 \\
10\end{array}$ & $\begin{array}{r}(94 \cdot 7) \\
(2 \cdot 4) \\
(2 \cdot 9)\end{array}$ \\
\hline Setting & $\begin{array}{l}\text { Community } \\
\text { Club } \\
\text { Water park } \\
\text { Outdoor area/park } \\
\text { Childcare } \\
\text { Childcare and community } \\
\text { Hotel } \\
\text { Private residence } \\
\text { Unknown }\end{array}$ & $\begin{array}{l}5 \\
4 \\
3 \\
3 \\
2 \\
1 \\
1 \\
1 \\
2\end{array}$ & $\begin{array}{r}(22 \cdot 7) \\
(18 \cdot 2) \\
(13 \cdot 6) \\
(13 \cdot 6) \\
(9 \cdot 1) \\
(4 \cdot 5) \\
(4 \cdot 5) \\
(4 \cdot 5) \\
(9 \cdot 1)\end{array}$ & $\begin{array}{r}227 \\
189 \\
8456 \\
295 \\
16 \\
63 \\
7 \\
3 \\
39\end{array}$ & $\begin{array}{r}(2 \cdot 4) \\
(2 \cdot 0) \\
(91 \cdot 0) \\
(3 \cdot 2) \\
(0 \cdot 2) \\
(0 \cdot 7) \\
(0 \cdot 1) \\
(0 \cdot 0) \\
(0 \cdot 4)\end{array}$ & $\begin{array}{l}\text { Outdoor area/park } \\
\text { Beach } \\
\text { Club } \\
\text { Camp } \\
\text { Unknown }\end{array}$ & $\begin{array}{l}4 \\
3 \\
1 \\
1 \\
2\end{array}$ & $\begin{array}{r}(36 \cdot 4) \\
(27 \cdot 3) \\
(9 \cdot 1) \\
(9 \cdot 1) \\
(18 \cdot 2)\end{array}$ & $\begin{array}{r}38 \\
231 \\
48 \\
4 \\
19\end{array}$ & $\begin{array}{r}(11 \cdot 2) \\
(67 \cdot 9) \\
(14 \cdot 1) \\
(1 \cdot 2) \\
(5 \cdot 6)\end{array}$ \\
\hline
\end{tabular}

* Multiple aetiological agents were identified during investigations of nine outbreaks. Giardia and Cryptosporidium were identified in the six treated recreational water-associated outbreaks and in two untreated recreational water-associated outbreaks. In one untreated recreational water-associated outbreak, Giardia and E. coli $\mathrm{O} 157: \mathrm{H} 7$ were identified ( $n=8$ cases).

$(72 \cdot 7 \%)$ and cases $(94 \cdot 7 \%)$ were associated with lakes. Outdoor areas/parks were the most frequent settings of untreated recreational water-associated outbreaks $(36 \cdot 4 \%)$, while beaches were the setting of the most resulting cases $(67 \cdot 9 \%)$.

For waterborne outbreaks associated with water other than drinking water or recreational water, the most commonly implicated water type was a river/ stream, which was linked to six outbreaks $(46 \cdot 2 \%)$ and $48.4 \%$ of outbreak cases. Two outbreaks ( $15 \cdot 4 \%$ ) were associated with a puddle, canal, or swamp; two outbreaks $(15.4 \%)$ were associated with wastewater or partially treated wastewater; one outbreak $(7 \cdot 7 \%)$ was associated with a spring, and two outbreaks had an unreported water type.

Most of the 38 foodborne outbreaks (60.5\%) had no food vehicle reported; these outbreaks resulted in half of the foodborne giardiasis outbreak cases. Of the 15 with a food implicated, produce $(20 \cdot 0 \%)$ was the most commonly implicated food category, followed by ice $(13 \cdot 3 \%)$ and fruit $(13 \cdot 3 \%)$. Raw vegetables, a salad bar, unspecified vegetables, and fresh fruit were implicated in the produce and fruit-associated outbreaks. Chicken salad, home-canned salmon, ice cream, oysters, and sandwiches were each linked to one outbreak. There were three outbreaks for which either multiple foods or a meal were implicated but the particular contaminated ingredient was undetermined. These included an outbreak linked to lettuce, onions, coffee, and tea; an outbreak linked to chicken parmesan and lettuce salad; and an outbreak for which the food items were not specified. Of the 36 outbreaks with a food preparation setting identified, the most common settings were restaurant or delicatessen (44.4\%), followed by private home $(19 \cdot 4 \%)$. Seven of nine foodborne outbreaks with information on contributing factors had involvement of a food worker or other food handler; one outbreak involving produce had contaminated raw product and process failures that permitted pathogen survival, and two outbreaks had factors related to inadequate cleaning or storage of food in a contaminated environment.

Six person-to-person outbreaks were linked to 28 cases of illness. Settings of person-to-person outbreaks 
included households $(n=3)$, childcare $(n=1)$, and unknown $(n=2)$. Three outbreaks and 20 outbreak cases resulted from animal contact transmission; these were associated with rabbits at a petting zoo, cattle at a farm, and a pet reptile at a long-term care facility.

\section{DISCUSSION}

This review and analysis of national giardiasis outbreak surveillance data highlights the historical and ongoing ability of Giardia to cause outbreaks through multiple transmission routes. To our knowledge, this analysis is the first of its kind to examine giardiasis outbreaks associated with all modes of transmission over several decades and to summarize the outbreaks in the context of changes to policies and disease surveillance activities. The results provide insight into the impact of general and pathogen-specific prevention measures already undertaken, including drinking water regulations, pool codes, and food codes. The findings also help clarify which transmission modes and preventive measures have been important drivers of giardiasis outbreaks in the United States and suggest additional areas to target with future prevention efforts.

Most reported giardiasis outbreaks and outbreak cases were associated with waterborne transmission. Giardia is moderately chlorine-tolerant and is able to survive in untreated or inadequately chlorinated drinking or recreational water. Giardia has a low infectious dose, infected persons can excrete large numbers of infectious cysts for prolonged periods of time, and cysts can survive in the environment. Thus, if faecal waste from one infected person is diluted in a water body or supply, many others can become infected with Giardia by ingesting contaminated recreational or drinking water. The Clean Water Act (CWA) of 1972, which regulates pollutant discharges and quality standards for surface waters, was one of the first regulations to control waste discharge into surface waters that could potentially be used for drinking, agriculture, or recreation [18].

While most of the waterborne giardiasis outbreaks and outbreak cases were drinking water-associated, the number of reported drinking water-associated outbreaks decreased after the 1980s, possibly resulting from a reduction in outbreaks associated with treatment deficiencies (i.e. circumstances at the treatment facility allowed contamination). The Safe Drinking Water Act (SDWA) of 1974 authorizes the U.S. EPA to regulate the public drinking water supply for health-based contaminants, largely by focusing on water-treatment standards. The 1996 amendments added additional measures to increase source water protection, operator training, and funding for water system improvements [16]. No outbreaks with untreated surface water deficiencies were reported after 1995. These decreases in the proportion of giardiasis outbreaks associated with treatment and surface water deficiencies followed the implementation of several key drinking water regulations, including the 1989 SWTR, which requires $99.9 \%$ removal or inactivation of Giardia in public water systems with surface water sources or groundwater sources influenced by surface water [19]. Additional protections from the 1998 Interim Enhanced Surface Water Treatment Rule, the 2002 Long Term 1 Enhanced Surface Water Treatment Rule, and the 2006 Long Term 2 Enhanced Surface Water Treatment Rule likely also help to reduce Giardia in public drinking water systems with surface water sources [20-22].

In contrast, untreated groundwater source and distribution system deficiencies were identified throughout the study period. The 2006 Ground Water Rule specifies monitoring criteria and corrective action requirements for public groundwater systems with documented deficiencies demonstrating a high risk for faecal contamination [23]. However, this rule does not address individual water systems (e.g. private wells), which the federal government does not have the authority to regulate. These systems were associated with about $8 \%$ of the drinking water-associated outbreaks in this analysis; however, these are difficult to detect by public health agencies and through outbreak surveillance, since they might only impact a single household or neighbourhood. Continued efforts to educate and motivate private well owners to inspect, maintain, and test the water from their private wells could improve water quality and reduce the spread of disease [24]. The continued occurrence of giardiasis outbreaks with distribution system deficiencies suggests that drinking water distribution system infrastructure vulnerabilities are an ongoing public health concern. In a separate analysis summarizing all drinking water-associated outbreaks in the United States from 1971-2006, distribution system deficiencies were linked to $10 \%$ of outbreaks, and untreated groundwater source deficiencies were linked to $30 \%$ of outbreaks, indicating that efforts to remediate and prevent these types of deficiencies could have widespread public health benefits that extend beyond Giardia prevention [25]. 
Giardiasis outbreaks occur in both treated and untreated recreational water venues. Outbreaks associated with treated recreational water venues are preventable and indicate inadequate operation of the implicated venues, including failure to maintain appropriate chlorine and $\mathrm{pH}$ levels. Violations of disinfectant level and $\mathrm{pH}$ code standards have been well-documented in routine inspections of public treated recreational water venues, including wading pools [26]. These violations in wading pools are especially risky for pathogen transmission, as young children have the highest rates of giardiasis and ingest water during swimming activities [11, 27]. Requiring operators of public treated recreational water venues to successfully complete training to operate these venues has been associated with improved water quality $[28,29]$.

In contrast to treated recreational water venues, untreated recreational waters, by their nature, have a lack of available chemical remediation options. The Beaches and Environmental Assessment and Coastal Health (BEACH) Act of 2000 sets national water quality monitoring and reporting standards for the Great Lakes and marine coastal recreational waters [30, 31]. Still, even on days where the water quality is considered acceptable for bathing by bacterial indicator standards, crowded beach waters might contain human pathogens, including Giardia and Cryptosporidium, likely because of direct microbial input from bathers and re-suspension of sediment [32, 33]. Ultimately, the occurrence of inadequately maintained disinfectant and $\mathrm{pH}$ levels in treated recreational water venues and the lack of chemical remediation options for untreated recreational water venues underscore the need for healthy swimming behaviours (e.g. not swimming while ill with diarrhoea) to minimize water contamination and thus help prevent pathogen transmission. Health communication campaigns can increase awareness of and possibly the practice of healthy swimming behaviours [34].

Poor hygiene practices by food handlers might have contributed to the occurrence of many foodborne giardiasis outbreaks: several of the outbreak reports cited a lack of hand washing and infectious, sometimes asymptomatic, food workers as the cause [35, 36]. Our finding that produce items were the most frequently identified foods in giardiasis outbreaks is consistent with studies of risk factors of sporadic giardiasis, which have found links between giardiasis and eating lettuce and green salads [37, 38]. There are numerous places in the production chain where produce can become contaminated, and many of the mechanisms of contamination have a water quality, sanitation, or hygiene component $[39,40]$. These include contamination by irrigation water or runoff in the field, by water used in processing and packing, or by unwashed hands during harvesting, processing, packing, transport, or at point-of-use [40-42]. Prevention of produce contamination is especially important, since fruits and vegetables are often eaten raw without a step to inactivate pathogens [43]. Implementation of the Food Safety Modernization Act (FSMA) Proposed Rule for Produce Safety, when finalized, is expected to prevent future produce-associated outbreaks by setting safety requirements for produce on farms during growing, harvesting, packing, and holding. Requirements include setting standards for personnel hygienic practices, establishing a water quality profile for agricultural water, treating and applying soil amendments, controlling potential hazards introduced by animals, and keeping equipment, buildings, and tools cleaned and maintained [44].

Outbreaks with person-to-person, animal contact, environmental, or unknown transmission modes were the least commonly reported; however, there were only 2 years of systematic data collection available for inclusion in this analysis. Published studies have implicated person-to-person transmission of giardiasis in institutional settings such as child care and nursing homes that resulted in disease spread to caregivers, other contacts, or into the community [45-48]. The case counts from these person-to-person outbreaks were higher than those for the outbreaks included in this analysis; however, these occurred before the implementation of NORS and were not reported to CDC. Animal contact was implicated in only three reported giardiasis outbreaks, consistent with current molecular epidemiological data suggesting that animal contact transmission of giardiasis is relatively uncommon because animals are more often infected with species-specific assemblages that do not cause disease in humans [7].

There were several limitations to this review and analysis. National surveillance systems do not capture all outbreaks that occur, and epidemiological, laboratory, and environmental health information are not uniformly collected during outbreak investigations. This limits inferences that can be made using outbreak surveillance data and underscores the usefulness of uniform data collection during outbreak investigations [49], in addition to systematic reporting. The peak in reported waterborne outbreaks seen here during a period of intensive waterborne disease surveillance in three states indicates that the sensitivity of 
passive outbreak surveillance could be low and that detection and reporting can improve if resources are allocated to increase surveillance capacity at the state level. Differences in public health capacity or reporting practices across states and over time should be considered when interpreting increases and decreases in reported outbreaks. Additionally, there were limited years of outbreak data for the non-water and non-food modes of transmission, thus caution should be exercised in interpreting the relative importance of the different modes of transmission in giardiasis outbreaks. The implementation of comprehensive enteric disease outbreak reporting through NORS is an important step to help standardize data collection across years and modes of transmission [12]. Additionally, the inclusion of multiple-pathogen outbreaks in our analysis means that the number of outbreak-associated cases reported here includes an unknown number of cases of other illnesses. In particular, the magnitude of some recreational waterassociated giardiasis outbreaks might have been driven by transmission of the extremely chlorinetolerant parasite Cryptosporidium [50]; omitting the nine muti-pathogen outbreaks would have excluded $90 \%$ of outbreak cases from the recreational water outbreaks.

In summary, this analysis of giardiasis outbreaks reported to CDC over 41 years suggests that these outbreaks can be prevented when resources are allocated for preventive measures. Regulations, facilities, and services for drinking water treatment and management appear to have prevented waterborne transmission of giardiasis in public surface water systems. Groundwater and distribution system vulnerabilities might be promising areas to target with future preventive measures. Treated recreational venue maintenance and operation, in combination with health promotion efforts to improve swimmer hygiene in both treated and untreated recreational waters could prevent outbreaks associated with these settings. For foodborne outbreaks, focusing on food handler and consumer hygiene and the prevention of produce contamination could prevent outbreaks.

Molecular epidemiology has the potential to expand our understanding of Giardia transmission. The United States does not systematically perform molecular typing on Giardia isolates nationally, and molecular studies are seldom undertaken in outbreak investigations. Implementation of a surveillance system that incorporates molecular-based laboratory testing of Giardia specimens could enable the detection of additional outbreaks, including those associated with distributed food products or animal contact. Our findings demonstrate the need and value in investing resources in public health surveillance activities as a way to help evaluate preventive measures already in place and suggest areas where future efforts might decrease illness incidence. Each outbreak provides valuable information about pathogen transmission, and the lessons learned from examining patterns in outbreaks over time can be used to prevent future disease.

\section{ACKNOWLEDGEMENTS}

The authors gratefully acknowledge the work of local, state, and territorial health departments in investigating and reporting outbreaks and thank Virginia Roberts for assistance with extracting and interpreting outbreak data, and Sarah Collier for assistance with analyses. This research was supported in part by an appointment to the Research Participation Program at the Centers for Disease Control and Prevention administered by the Oak Ridge Institute for Science and Education through and interagency agreement between the U.S. Department of Energy and CDC.

The findings and conclusions in this article are those of the authors, and do not necessarily represent the official position of the U.S. CDC.

\section{DECLARATION OF INTEREST}

None.

\section{REFERENCES}

1. Kappus KD, et al. Intestinal parasitism in the United States: update on a continuing problem. American Journal of Tropical Medicine and Hygiene 1994; 50: 705-713.

2. Scallan E, et al. Foodborne illness acquired in the United States - major pathogens. Emerging Infectious Diseases 2011; 17: 7-15.

3. Collier SA, et al. Direct healthcare costs of selected diseases primarily or partially transmitted by water. Epidemiology and Infection 2012; 140: 2003-2013.

4. Huang DB, White AC. An updated review on Cryptosporidium and Giardia. Gastroenterology Clinics of North America 2006; 35: 291-314.

5. Nash TE, et al. Experimental human infections with Giardia lamblia. Journal of Infectious Diseases 1987; 156: 974-984.

6. Rendtorff RC. The experimental transmission of human intestinal protozoan parasites. II. Giardia lamblia cysts given in capsules. American Journal of Hygiene 1954; 59: $209-220$. 
7. Xiao L, Fayer R. Molecular characterisation of species and genotypes of cryptosporidium and giardia and assessment of zoonotic transmission. International Journal for Parasitology 2008; 38: 1239-1255.

8. Danciger M, Lopez M. Numbers of giardia in the feces of infected children. American Journal of Tropical Medicine and Hygiene 1975; 24: 237-242.

9. Pickering LK, et al. Occurrence of Giardia lamblia in children in day care centers. Journal of Pediatrics 1984; 104: 522-526.

10. Yoder JS, et al. Giardiasis surveillance - United States, 2009-2010. Morbidity and Mortality Weekly Report. Surveillance Summaries 2012; 61: 13-23.

11. Painter JE, et al. Giardiasis Surveillance-United States, 2011-2012. Morbidity and Mortality Weekly Report. Surveillance Summaries 2015; 64: 15-25.

12. Hall AJ, et al. Acute gastroenteritis surveillance through the National Outbreak Reporting System, United States. Emerging Infectious Disease 2013; 19: 1305-1309.

13. Gargano JW, et al. Surveillance for waterborne disease outbreaks associated with drinking water and other nonrecreational water - United States, 2009-2010. Morbidity and Mortality Weekly Report 2013; 62: 714-720.

14. Gould LH, et al. Surveillance for foodborne disease outbreaks - United States, 1998-2008. Morbidity and Mortality Weekly Report Surveillance Summaries 2013; 62: 1-34.

15. Hlavsa MC, et al. Recreational water-associated disease outbreaks - United States, 2009-2010. Morbidity and Mortality Weekly Report 2014; 63: 6-10.

16. Environmental Protection Agency. Understanding the Safe Drinking Water Act (http://water.epa.gov/law sregs/guidance/sdwa/upload/2009_08_28_sdwa_fs_30ann_ sdwa_web.pdf). Accessed 26 May 2015.

17. Harter L, et al. A three-state study of waterborne disease surveillance techniques. American Journal of Public Health 1985; 75: 1327-1328.

18. Envrionmental Protection Agency. Clean Water Act 1972; 33 U.S.C. $\$ 1251$ et seq.

19. Environmental Protection Agency. Drinking water, national primary drinking water regulations, filtration, disinfection, turbidity, Giardia lamblia, viruses, Legionella, and heterotrophic bacteria; Final Rule. Federal Register 1989, 54: 27486-27541.

20. Environmental Protection Agency. National primary drinking water regulations: interim enhanced surface water treatment; Final Rule. Federal Register 1998; 63: 69478-69521.

21. Environmental Protection Agency. National primary drinking water regulations: long term 1 enhanced surface water treatment rule; Final Rule. Federal Register 2002; 67: 1812-1844.

22. Environmental Protection Agency. National primary drinking water regulations: long term 2 enhanced surface water treatment rule; Final Rule. Federal Register 2006; 71: 654-786.

23. Environmental Protection Agency. National Primary Drinking Water Regulations: Ground Water Rule; Final Rule. Federal Register 2006; 71: 65573-65660.
24. Knobeloch $\mathbf{L}$, et al. Private drinking water quality in rural Wisconsin. Journal of Environmental Health 2013; 75: 16-20.

25. Craun GF, et al. Causes of outbreaks associated with drinking water in the United States from 1971 to 2006. Clinical Microbiology Reviews 2010; 23: 507-528.

26. Centers for Disease Control and Prevention. Violations identified from routine swimming pool inspections selected states and counties, United States, 2008. Morbidity and Mortality Weekly Report 2010; 59: 582-587.

27. Dufour AP, et al. Water ingestion during swimming activities in a pool: a pilot study. Journal of Water and Health 2006; 4: 425-430.

28. Buss BF, et al. Association between swimming pool operator certification and reduced pool chemistry violations - Nebraska, 2005-2006. Journal of Environmental Health 2009; 71: 36-40.

29. Johnston K, Kinziger M. Certified operators: does certification provide significant results in real-world pool and spa chemistry? International Journal of Aquatic Research and Education 2007; 1: 18-33.

30. Environmental Protection Agency. Beaches Environmental Assessment and Coastal Health Act of 2000. Public Law 106-284 (http://water.epa.gov/lawsregs/ lawsguidance/beachrules/upload/2009_04_13_beaches_ files_beachbill.pdf). Accessed 26 May 2015.

31. Wade TJ, et al. Rapidly measured indicators of recreational water quality are predictive of swimmingassociated gastrointestinal illness. Environmental Health Perspectives 2006; 114: 24-28.

32. Graczyk TK, et al. Relationships among bather density, levels of human waterborne pathogens, and fecal coliform counts in marine recreational beach water. Parasitology Research 2010; 106: 1103-1108.

33. Graczyk TK, et al. Bather density and levels of cryptosporidium, giardia, and pathogenic microsporidian spores in recreational bathing water. Parasitology Research 2007; 101: 1729-1731.

34. Hlavsa MC, et al. Promotion of healthy swimming after a statewide outbreak of cryptosporidiosis associated with recreational water venues-Utah, 20082009. Morbidity and Mortality Weekly Report 2012; 61: 348 .

35. Mintz ED, et al. Foodborne giardiasis in a corporate office setting. Journal of Infectious Diseases 1993; 167: 250-253.

36. Quick R, et al. Restaurant-associated outbreak of giardiasis. Journal of Infectious Diseases 1992; 166: 673-676.

37. Espelage W, et al. Characteristics and risk factors for symptomatic Giardia lamblia infections in Germany. BMC Public Health 2010;10-41.

38. Stuart JM, et al. Risk factors for sporadic giardiasis: a case-control study in southwestern England. Emerging Infectious Diseases 2003; 9: 229-233.

39. Ailes EC, et al. Microbial concentrations on fresh produce are affected by postharvest processing, importation, and season. Journal of Food Protection 2008; 71: 2389-2397. 
40. Lynch MF, Tauxe RV, Hedberg CW. The growing burden of foodborne outbreaks due to contaminated fresh produce: risks and opportunities. Epidemiology and Infection 2009; 137: 307-315.

41. Lewis HC, et al. Outbreaks of Shigella sonnei infections in Denmark and Australia linked to consumption of imported raw baby corn. Epidemiology and Infection 2009; 137: 326-334.

42. Sivapalasingam S, et al. A multistate outbreak of Salmonella enterica serotype Newport infection linked to mango consumption: impact of water-dip disinfestation technology. Clinical Infectious Diseases 2003; 37: 1585-1590.

43. Burnett SL, Beuchat LR. Human pathogens associated with raw produce and unpasteurized juices, and difficulties in decontamination. Journal of Industrial Microbiology \& Biotechnology 2001; 27: 104-110.

44. Food and Drug Administration. Standards for the growing, harvesting, packing, and holding of produce for human consumption; Proposed Rule. Federal Register 2014; 79: 58433-58473.
45. Black RE, et al. Giardiasis in day-care centers: evidence of person-to-person transmission. Pediatrics 1977; 60: 486-491.

46. Polis MA, et al. Transmission of Giardia lamblia from a day care center to the community. American Journal of Public Health 1986; 76: 1142-1144.

47. White KE, et al. An outbreak of giardiasis in a nursing home with evidence for multiple modes of transmission. Journal of Infectious Diseases 1989; 160: 298-304.

48. Katz DE, et al. Prolonged outbreak of giardiasis with two modes of transmission. Epidemiology and Infection 2006; 134: 935-941.

49. Council to Improve Foodborne Outbreak Response (CIFOR). Guidelines for foodborne disease outbreak response, 2nd edn. Atlanta: Council of State and Territorial Epidemiologists 2014 (http://www.cifor.us/ documents/CIFOR\%20Industry\%20Guidelines/CIFORIndustry-Guideline.pdf). Accessed 26 May 2015.

50. Centers for Disease Control and Prevention. Communitywide cryptosporidiosis outbreak - Utah, 2007. Morbidity and Mortality Weekly Report 2008; 57: 989-993. 